\title{
Relationship between fish intake, $n-3$ fatty acids, mercury and risk markers of CHD (National Health and Nutrition Examination Survey 1999-2002)
}

\author{
Kimberly M Smith ${ }^{1,2, *}$, Leila M Barrai ${ }^{2}$, Mark Kantor ${ }^{1}$ and Nadine R Sahyoun ${ }^{1}$ \\ 'Department of Nutrition and Food Science, University of Maryland, College Park, MD, USA: ${ }^{2}$ Exponent, Inc., \\ The Lenz, 1 st Floor, Hornbeam Park, Harrogate, North Yorkshire, HG2 8RE, UK
}

Submitted 26 November 2007: Accepted 15 September 2008: First published online 6 November 2008

\begin{abstract}
Background: Fish consumption has been shown to be inversely associated with CHD, which may be due to $n-3$ fatty acids. The $n-3$ fatty acids, EPA and DHA, are naturally found only in marine sources. Dietary intakes of methylmercury from certain fish have been hypothesized to increase the risk of CHD.

Objective: To investigate the relationship between $30 \mathrm{~d}$ fish frequency consumption (assessed by FFQ), total blood $\mathrm{Hg}$ concentrations and risk markers of CHD in women aged 16-49 years participating in the National Health and Nutrition Examination Survey 1999-2002.

Design: Multiple linear regression analyses were used to test (i) the relationships between $30 \mathrm{~d}$ fish frequency consumption and five CHD risk markers, i.e. HDL cholesterol (HDL-C), LDL cholesterol, total cholesterol, TAG and C-reactive protein (CRP); and (ii) if total blood $\mathrm{Hg}$ attenuated any associations between fish consumption and CHD risk markers in non-pregnant, non-diabetic females aged 16-49 years.

Results: Total $30 \mathrm{~d}$ fish frequency consumption was negatively associated with CRP $(b=-0 \cdot 10,95 \% \mathrm{CI}-0 \cdot 19,-0 \cdot 02, P=0 \cdot 015)$ and positively associated with HDL-C $(b=1 \cdot 40,95 \%$ CI $0 \cdot 31,2 \cdot 50, P=0 \cdot 014)$. Adjustment for other risk factors did not significantly attenuate the associations. Despite the collinearity between fish and $\mathrm{Hg}$, there is a protective association between fish intake and CHD risk factors.

Conclusions: The levels of DHA + EPA and other nutrients in fish may be adequate to offset the hypothesized risks of heart disease related to ingesting $\mathrm{Hg}$ from fish.
\end{abstract}

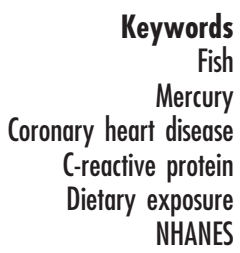

cury

y C-reactive protein NHANES
Fish and fish oils containing the $n$ - 3 fatty acids DHA and EPA have been shown to have cardioprotective attributes in both healthy individuals and those at high risk of $\mathrm{CHD}^{(1-4)}$. The chief dietary sources of DHA and EPA are fatty fish such as mackerel, lake trout, herring, tuna, sardines and salmon, as well as dietary supplements. Consumption of DHA and EPA and fish containing these fatty acids has been shown to reduce blood lipid concentrations of LDL cholesterol (LDL-C), total cholesterol (TC) and TAG, and to raise concentrations of $\mathrm{HDL}$ cholesterol (HDL-C) ${ }^{(5-7)} \cdot n-3$ Fatty acid intake is also associated with a reduction in plasma biomarkers of inflammation such as C-reactive protein $(\mathrm{CRP})^{(5)}$. The physiological effects of DHA and EPA include lowering plasma TAG concentrations, inhibiting plaque formation, decreasing platelet aggregation and reducing arrhythmias ${ }^{(8-10)}$.

Fish also contains methylmercury (MeHg), an environmental contaminant derived from industrial waste and the burning of fossil fuels. MeHg makes its way into streams, lakes and oceans where it becomes incorporated into the food chain of marine animals ${ }^{(11)}$. The main focus of $\mathrm{MeHg}$ has been its effects on neurodevelopment in children $^{(12-14)}$. To monitor exposure to $\mathrm{MeHg}$, the National Health and Nutrition Examination Survey (NHANES) measured blood and hair $\mathrm{Hg}$ concentrations in the sensitive populations of children and women of childbearing age. There is more recent evidence that, in addition to its effects on neurodevelopment in children, $\mathrm{MeHg}$ may increase the risk of CHD by promoting the formation of free radicals and compromising the function of antioxidants that neutralize these agents ${ }^{(15)}$. Therefore, it is possible that consuming fish contaminated with $\mathrm{MeHg}$ may increase the risk of CHD.

The hypothesis that $\mathrm{MeHg}$ attenuates associations between fish consumption and CHD risk markers remains unproven. A review of seven epidemiological studies 
conducted to date (five in men, one in women and one with both men and women) suggests an association between MeHg exposure and greater CHD risk, including acute myocardial infarction, but none of these studies addressed the combined effect of fish or $n$ - 3 fatty acid intake and $\mathrm{MeHg}$ on risk markers of $\mathrm{CHD}^{(15-19)}$. Therefore the objective of the current study was to investigate relationships between $30 \mathrm{~d}$ frequency of fish intake, total blood $\mathrm{Hg}$ concentrations and risk markers of CHD in women aged 16-49 years who participated in NHANES 1999-2002. Indicators of CHD risk examined include blood concentrations of TC, LDL-C, HDL-C, TAG and the inflammatory marker CRP.

\section{Materials and methods}

The NHANES 1999-2002 database was used to investigate relationships between fish consumption, total blood $\mathrm{Hg}$ and risk markers of CHD in women aged 16-49 years. The NHANES is a stratified, multistage probability sample of the civilian non-institutionalized US population which interviews approximately 5000 people per survey year. Respondents are interviewed in their homes and also complete a health examination component in mobile examination centres. Low-income persons, adolescents 12-19 years of age, African-Americans and MexicanAmericans are over-sampled ${ }^{(20)}$.

\section{Independent variables}

Fish intake of women aged 16-49 years was assessed as the total number of fish meals reported consumed in a $30 \mathrm{~d}$ fish FFQ in the NHANES 1999-2002. The NHANES participants did not provide data on the portion sizes of fish reported consumed in the fish FFQ. In the present analysis, total fish frequency of consumption data for women aged 16-49 years was grouped into four categories: $0,1-4,5-8$ or $\geq 9$ times/30d. Shellfish were omitted from the analysis because they are low in $\mathrm{Hg}$. For individuals in each of the four fish consumption categories, mean blood lipids, CRP, total blood $\mathrm{Hg}$ and nutrient concentrations along with descriptive statistics for selected demographic variables were calculated. The summary statistics were derived using the 4-year statistical weights and adjusting for the statistical design of the survey as recommended by the NHANES analytical guidelines $^{(20)}$.

Dietary exposure to $\mathrm{Hg}$ was evaluated in this study using total blood $\mathrm{Hg}$ concentrations measured in NHANES 1999-2002 female participants aged 16-49 years.

\section{Dependent variables}

The dependent variables of interest in this study were TC, HDL-C and CRP. Because TAG data were available for a limited number of participants in the NHANES 1999-2002, a separate sensitivity analysis was conducted using serum TAG and LDL-C concentrations.

\section{Covariate variables}

Covariates were included in the regression models to take into account demographic, lifestyle and nutritional factors. Demographic and lifestyle variables were self-reported unless otherwise noted and included age (grouped for the present analysis into four categories: 16-19, 20-29, 30-39 and 40-49 years), ethnicity (non-Hispanic white, nonHispanic black, Mexican-American, other Hispanic and other), BMI (calculated as measured weight in kilograms divided by the square of measured height in metres), educational attainment (less than high school, high school or General Educational Development, greater than high school), physical activity (separated into low, moderate and heavy levels of daily activity), prescription drug use (anti-inflammatory or lipid-lowering), serum cotinine concentrations (a measure of exposure to tobacco) and medical history of heart disease (physician-diagnosed diseases). The diagnoses of congestive heart failure, CHD, angina, heart attack or stroke were categorized as heart disease. Intake of individual nutrients was derived from the $24 \mathrm{~h}$ dietary recall interview and was based on calculations by the National Center for Health Statistics (NCHS). Nutrient intakes (energy, fibre, MUFA, SFA, TC, vitamin C, alcohol and Se) were treated as continuous variables in all models. Nutrients that were omitted from the models because they were not significantly associated with the dependent variables or caused collinearity included protein, carbohydrate, total fat and total PUFA.

\section{Cobort for analysis}

The sample for the present study was limited to women for whom data for the independent and dependent variables of interest were available. The NHANES 1999-2002 dataset contains a total of 10790 women, including 4084 women aged 16-49 years. Our sample was further restricted to women having measurements for total blood $\mathrm{Hg}$ ( $n$ 3637), CRP ( $n$ 3608), $24 \mathrm{~h}$ dietary recall interview ( $n$ 3458), $30 \mathrm{~d}$ fish FFQ ( $n$ 3456), TC ( $n$ 3434) and HDL-C ( $n$ 3435). LDL-C and TAG data were collected on only a subset of women, reducing the sample size to 1726 prior to testing for confounding variables.

Women were excluded from all analyses if they reported on the demographic questionnaire that they were pregnant $(n$ 704), if a doctor had told them they were diabetic ( $n$ 104) or if their $24 \mathrm{~h}$ dietary recall interview was coded by NCHS as unreliable ( $n$ 207). This occurred if $>25 \%$ of foods reported consumed had missing descriptive information, $>15 \%$ of foods had missing quantities eaten or if a meal did not include at least one identified food. In addition, 211 women who did not have 4-year statistical weights were excluded. The numbers excluded are not mutually exclusive. After these adjustments were made, the sample size was reduced to 1245 women for the analysis of the major dependent variables, while 577 of the 1245 eligible women were included in the sensitivity analyses for LDL-C and TAG. 


\section{Statistical metbods}

The STATA statistical software package version $7 \cdot 0$ (Stata Corporation, College Station, TX, USA) was used to conduct all statistical analyses including the univariate summaries and multiple regression models. All estimates were derived using the 4-year statistical weights based upon mobile examination centre participation and adjusting for survey design. Regression analyses were conducted using the survey regression commands in STATA. The distributions of continuous variables were tested for normality using the Shapiro-Wilk test and data were transformed to achieve normality when necessary. Prior to analysis, log transformations were done on CRP and total blood $\mathrm{Hg}$ values, and a square-root transformation was performed on the total reported $30 \mathrm{~d}$ fish food frequency values ${ }^{(21)}$.

The following hypotheses were tested:

1. Fish intake is negatively associated with TC and CRP concentrations, and positively associated with HDL-C and total blood $\mathrm{Hg}$ concentrations.

2. Total blood $\mathrm{Hg}$ will attenuate any associations demonstrated between fish consumption and CHD risk markers.

We tested the effects of dietary $24 \mathrm{~h}$ intakes of $n$-3 PUFA on TC, CRP and HDL-C and the effects of total blood $\mathrm{Hg}$ on these associations; however, all results were not significant and thus are excluded from the current paper.

The sample was stratified into categories defined by total frequency of fish consumption in the past $30 \mathrm{~d}$ $(0,1-4,5-8$ and $\geq 9$ times/30 d). Means of all continuous variables for each of the three fish-consuming groups were compared with those of the fish non-consuming group using the adjusted Wald test.
The associations between total frequency of fish consumption in the past $30 \mathrm{~d}$, blood lipids and CRP concentrations were tested using multiple linear regression analyses. The initial models (Model 1) adjusted for energy intake and age (separated by decade, with women aged 16-19 years serving as the reference population). To adjust for potential confounding, subsequent multivariate models included known CHD risk factors.

Specifically, Model 2 adjusted for the variables in Model 1 as well as for lifestyle, dietary habits and medical history of arthritis and CHD. Model 2 also included adjustments for prescription drug use (anti-inflammatory or lipid-lowering), ethnicity, educational attainment (indicator variables) and continuous variables such as BMI, smoking (measured as serum cotinine) and $24 \mathrm{~h}$ dietary recall interview intakes of total energy, fibre, SFA, MUFA, vitamin C, Se and alcohol (continuous variables).

Model 3 included total blood $\mathrm{Hg}$ concentrations (log) in addition to the variables included in Model 2. The analyses were conducted separately for each of the blood lipids and CRP. The sample for all multiple linear regression analyses was limited to women aged 16-49 years with valid data for all variables included in Model 3 ( $n$ 1245).

\section{Results}

\section{Characteristics of the population}

Demographic and lifestyle characteristics, nutrient intakes and blood biomarkers of CHD risk by fish consumption category are summarized in Tables $1-3$. The 1245 nonpregnant women that constituted the study sample had an average age of 32.5 ( $\mathrm{SE} 0.4$ ) years and an average BMI

Table 1 Characteristics of the study sample by fish consumption group: sub-sample of women aged $16-49$ years participating in the National Health and Nutrition Examination Survey 1999-2002

\begin{tabular}{|c|c|c|c|c|c|c|c|c|c|}
\hline \multirow[b]{3}{*}{ Characteristic } & & & \multicolumn{6}{|c|}{ Fish consumers } & \multirow[b]{3}{*}{$P^{*}$} \\
\hline & \multicolumn{2}{|c|}{$\begin{array}{l}\text { Fish non-consumers } \\
\qquad(n \text { 441) }\end{array}$} & \multicolumn{2}{|c|}{$\begin{array}{l}1-4 \text { times } / 30 \mathrm{~d} \\
(n \text { 616) }\end{array}$} & \multicolumn{2}{|c|}{$\begin{array}{l}5-8 \text { times } / 30 \mathrm{~d} \\
(n \text { 131) }\end{array}$} & \multicolumn{2}{|c|}{$\begin{array}{l}\geq 9 \underset{(n 57)}{\operatorname{times}} / 30 \mathrm{~d} \\
(n 57)\end{array}$} & \\
\hline & Mean or $\%$ & SE & Mean or $\%$ & SE & Mean or $\%$ & SE & Mean or $\%$ & SE & \\
\hline Age (years) & $28 \cdot 9$ & 0.6 & $33 \cdot 5$ & 0.5 & $35 \cdot 4$ & $1 \cdot 2$ & 33.9 & 1.5 & $<0.00001$ \\
\hline BMI $\left(\mathrm{kg} / \mathrm{m}^{2}\right)$ & $26 \cdot 0$ & 0.6 & $26 \cdot 6$ & 0.3 & $25 \cdot 8$ & $0 . \overline{6}$ & $26 \cdot 9$ & 0.9 & NS \\
\hline \multicolumn{10}{|l|}{ Ethnicity (\%) } \\
\hline Mexican-Ámerican & $43 \cdot 2$ & & $48 \cdot 0$ & & $6 \cdot 4$ & & $2 \cdot 4$ & & \\
\hline Non-Hispanic white & $26 \cdot 7$ & & $54 \cdot 0$ & & $14 \cdot 2$ & & $5 \cdot 1$ & & \\
\hline Non-Hispanic black & $24 \cdot 4$ & & $51 \cdot 8$ & & $16 \cdot 3$ & & $7 \cdot 5$ & & \\
\hline Other Hispanic and other & $26 \cdot 2$ & & $53 \cdot 0$ & & $10 \cdot 5$ & & $10 \cdot 3$ & & \\
\hline Serum cotinine $(\mathrm{ng} / \mathrm{ml})$ & $46 \cdot 1$ & $6 \cdot 8$ & $46 \cdot 8$ & $6 \cdot 8$ & $39 \cdot 7$ & $6 \cdot 7$ & $15 \cdot 0$ & $6 \cdot 2$ & 0.0043 \\
\hline \multicolumn{10}{|l|}{ Physical activity (\%) } \\
\hline Little or no exerciset & $29 \cdot 4$ & & $54 \cdot 5$ & & $11 \cdot 3$ & & $4 \cdot 8$ & & \\
\hline Moderate exercise $\ddagger$ & $26 \cdot 3$ & & $52 \cdot 0$ & & $15 \cdot 4$ & & $6 \cdot 3$ & & \\
\hline Heavy exercise§ & $28 \cdot 1$ & & $55 \cdot 7$ & & $10 \cdot 3$ & & $5 \cdot 9$ & & \\
\hline
\end{tabular}

Summaries are presented as means with their standard error for continuous variables or as percentage in each category for categorical variables.

${ }^{*}$ Adjusted Wald test to test the accumulated difference of all fish consumers $v$. fish non-consumers (NS, $P>0 \cdot 05$ ).

tLittle or no regular recreation, sport or physical activity and avoids walking or exertion.

fLittle or no regular recreation, sport or physical activity but walks for pleasure and occasionally exercise; participating regularly in recreation or work requiring modest physical activity for 10 to $60 \mathrm{~min} /$ week.

$\S$ Participating regularly in recreation or work requiring modest physical activity for more than 60 min/week; participating regularly in heavy physical activity for less than $30 \mathrm{~min} /$ week; participating regularly in heavy physical activity for 30-60 min/week; participating regularly in heavy physical activity for $1-3 \mathrm{~h} /$ week; participating regularly in heavy physical activity for more than $3 \mathrm{~h} /$ week. 
Table 2 Nutrient intake profile of the study sample by fish consumption group: sub-sample of women aged 16-49 years participating in the National Health and Nutrition Examination Survey (NHANES) 1999-2002

\begin{tabular}{|c|c|c|c|c|c|c|c|c|c|}
\hline \multirow[b]{3}{*}{ Nutrient ${ }^{\star}$} & & & \multicolumn{6}{|c|}{ Fish consumers } & \multirow[b]{3}{*}{$P+$} \\
\hline & \multicolumn{2}{|c|}{$\begin{array}{l}\text { Fish non-consumers } \\
\qquad(n 441)\end{array}$} & \multicolumn{2}{|c|}{$\begin{array}{l}1-4 \text { times/30 d } \\
(n 616)\end{array}$} & \multicolumn{2}{|c|}{$\begin{array}{c}5-8 \text { times } / 30 \mathrm{~d} \\
(n 131)\end{array}$} & \multicolumn{2}{|c|}{$\begin{array}{c}\geq 9 \text { times } / 30 \mathrm{~d} \\
(n 57)\end{array}$} & \\
\hline & Mean & SE & Mean & SE & Mean & SE & Mean & SE & \\
\hline Energy $(\mathrm{kJ} / \mathrm{d})$ & 8025 & 177 & 8263 & 151 & 8828 & 328 & 9422 & 511 & 0.02 \\
\hline Protein (\% of energy) & $13 \cdot 8$ & 0.4 & $14 \cdot 3$ & 0.2 & $14 \cdot 9$ & 0.4 & $16 \cdot 5$ & $0 \cdot 8$ & 0.0003 \\
\hline Carbohydrate ( $\%$ of energy) & $54 \cdot 1$ & 0.9 & $51 \cdot 2$ & 0.5 & $51 \cdot 2$ & $1 \cdot 2$ & $46 \cdot 8$ & $2 \cdot 2$ & $0 \cdot 0018$ \\
\hline Fibre (\% of energy) & $2 \cdot 8$ & $0 \cdot 1$ & $2 \cdot 9$ & $0 \cdot 1$ & $2 \cdot 9$ & $0 \cdot 2$ & $2 \cdot 9$ & $0 \cdot 2$ & 0.0204 \\
\hline Fat (\% of energy) & $31 \cdot 8$ & $0 \cdot 7$ & 33.9 & 0.5 & $33 \cdot 1$ & 0.9 & $35 \cdot 7$ & $1 \cdot 9$ & NS \\
\hline SFA (\% of energy) & $10 \cdot 6$ & $0 \cdot 3$ & $11 \cdot 2$ & $0 \cdot 2$ & $10 \cdot 7$ & $0 \cdot 3$ & $11 \cdot 1$ & $0 \cdot 8$ & NS \\
\hline MUFA (\% of energy) & $11 \cdot 9$ & $0 \cdot 3$ & $12 \cdot 6$ & $0 \cdot 2$ & $12 \cdot 0$ & $0 \cdot 3$ & $13 \cdot 3$ & $0 \cdot 6$ & 0.023 \\
\hline PUFA (\% of energy) & $6 \cdot 5$ & $0 \cdot 2$ & $7 \cdot 0$ & $0 \cdot 2$ & $7 \cdot 0$ & $0 \cdot 3$ & $8 \cdot 0$ & 0.5 & NS \\
\hline Alcohol intake (\% of energy) & $1 \cdot 9$ & $0 \cdot 4$ & $2 \cdot 4$ & $0 \cdot 3$ & $2 \cdot 6$ & $0 \cdot 5$ & $2 \cdot 8$ & 0.9 & NS \\
\hline Cholesterol (g/1000 kJ) & $27 \cdot 6$ & $1 \cdot 8$ & $28 \cdot 3$ & $1 \cdot 1$ & $30 \cdot 4$ & $1 \cdot 7$ & $32 \cdot 8$ & 3.5 & NS \\
\hline Vitamin C (mg/1000 kJ) & $10 \cdot 9$ & $1 \cdot 0$ & $10 \cdot 1$ & $0 \cdot 6$ & $10 \cdot 9$ & $1 \cdot 0$ & $11 \cdot 9$ & $1 \cdot 6$ & NS \\
\hline $\mathrm{Se}(\mu \mathrm{g} / 1000 \mathrm{~kJ})$ & $10 \cdot 7$ & $0 \cdot 4$ & $11 \cdot 4$ & $0 \cdot 2$ & $12 \cdot 4$ & 0.5 & $13 \cdot 6$ & $0 \cdot 8$ & 0.0169 \\
\hline $\mathrm{DHA}+\mathrm{EPA}$ (\% of energy) & 0.02 & 0.01 & 0.04 & 0.004 & 0.07 & $0 \cdot 02$ & $0 \cdot 19$ & 0.05 & $<0.00001$ \\
\hline
\end{tabular}

${ }^{*}$ Nutrients calculated by NHANES from the $24 \mathrm{~h}$ dietary recall interview.

tAdjusted Wald test to test the accumulated difference of all fish consumers $v$. fish non-consumers (NS, $P>0.05$ ).

Table 3 Blood lipids, C-reactive protein and total blood mercury concentrations by fish consumption group: sub-sample of women aged 16-49 years participating in the National Health and Nutrition Examination Survey 1999-2002

\begin{tabular}{|c|c|c|c|c|c|c|c|c|c|}
\hline \multirow[b]{3}{*}{ Variable } & & & \multicolumn{6}{|c|}{ Fish consumers } & \multirow[b]{3}{*}{$P \|$} \\
\hline & \multicolumn{2}{|c|}{$\begin{array}{l}\text { Fish non-consumers } \\
\qquad(n 441)^{\star}\end{array}$} & \multicolumn{2}{|c|}{$\begin{array}{l}1-4 \text { times } / 30 \mathrm{~d} \\
(n \text { 616) } \dagger\end{array}$} & \multicolumn{2}{|c|}{$\begin{array}{c}5-8 \text { times } / 30 \mathrm{~d} \\
(n 131) \ddagger\end{array}$} & \multicolumn{2}{|c|}{$\begin{array}{l}\geq 9 \text { times } / 30 \mathrm{~d} \\
(n 57) \S\end{array}$} & \\
\hline & Mean & SE & Mean & SE & Mean & SE & Mean & SE & \\
\hline $\mathrm{TC}(\mathrm{mg} / \mathrm{dl})$ & 184.9 & $2 \cdot 6$ & $190 \cdot 6$ & $1 \cdot 4$ & $185 \cdot 5$ & $4 \cdot 5$ & $191 \cdot 9$ & $3 \cdot 4$ & NS \\
\hline HDL-C (mg/dl) & $52 \cdot 2$ & $1 \cdot 2$ & $57 \cdot 1$ & 0.9 & $55 \cdot 6$ & $1 \cdot 2$ & $59 \cdot 5$ & $2 \cdot 0$ & 0.0011 \\
\hline LDL-C (mg/dl) & $111 \cdot 4$ & $3 \cdot \overline{7}$ & $109 \cdot 6$ & $1 \cdot 9$ & $108 \cdot 9$ & $5 \cdot 2$ & $114 \cdot 6$ & 3.9 & NS \\
\hline TAG (mg/dl) & $101 \cdot 3$ & $5 \cdot 0$ & $104 \cdot 2$ & $3 \cdot 5$ & $109 \cdot 5$ & $13 \cdot 7$ & $95 \cdot 8$ & $10 \cdot 4$ & NS \\
\hline CRP (mg/l) & 0.35 & 0.03 & 0.39 & 0.03 & 0.27 & 0.04 & 0.30 & 0.08 & NS \\
\hline Total blood Hg $(\mu \mathrm{g} / \mathrm{l})$ & $0 \cdot 6$ & 0.05 & $1 \cdot 6$ & $0 \cdot 1$ & $2 \cdot 2$ & $0 \cdot 3$ & $4 \cdot 2$ & $0 \cdot 7$ & $<0.00001$ \\
\hline
\end{tabular}

TC, total cholesterol; HDL-C, HDL cholesterol; LDL-C, LDL cholesterol; CRP, C-reactive protein.

${ }^{*} n 195$ for LDL-C and $n 213$ for TAG.

tn 288 for LDL-C and $n 304$ for TAG.

$\ddagger n 64$ for LDL-C and $n 67$ for TAG.

$\$ n 30$ for LDL-C and $n 32$ for TAG.

IIAdjusted Wald test to test the accumulated difference of all fish consumers $v$. fish non-consumers (NS, $P>0 \cdot 05)$.

of $26 \cdot 3(\mathrm{se} 0 \cdot 22) \mathrm{kg} / \mathrm{m}^{2}$. The reported average daily energy intake of the sample was slightly less than $8500 \mathrm{~kJ} / \mathrm{d}$ $(2000 \mathrm{kcal} / \mathrm{d})$, i.e. $8341(\mathrm{se} 106 \cdot 7) \mathrm{kJ} / \mathrm{d}$. The study sample reported an average of $2 \cdot 9(\mathrm{SE} 0 \cdot 13)$ fish meals over $30 \mathrm{~d}$ (less than one fish meal per week) and had an average DHA + EPA intake of $0 \cdot 1(\operatorname{sE} 0 \cdot 01) \mathrm{g}$ calculated from the $24 \mathrm{~h}$ dietary recall interview, confirming a low fish intake.

The majority of the sample of women aged 16-49 years consumed fish 1-4 times/30 d. Study participants who classified themselves as 'other Hispanic' and 'other' had the greatest percentage of regular fish consumers (fish $\geq 9$ times/30 d; $10 \%$ ). The data also suggested that fish consumers were less likely to smoke and to be exposed to second-hand smoke (Table 1 ).

Of the blood lipids tested, HDL-C concentrations were higher in the fish consumption groups compared with the fish non-consumers $(P=0 \cdot 0011)$, while no differences existed across groups for any of the other lipids or CRP (Table 3). The women in this sample had desirable average blood lipid profiles; TC was $188 \cdot 4$ (SE 1.4) mg/dl and HDL-C was $55 \cdot 7(\mathrm{se} 0 \cdot 7) \mathrm{mg} / \mathrm{dl}$. The average CRP was $0 \cdot 36(\operatorname{se} 0 \cdot 02) \mathrm{mg} / \mathrm{l}$, below the value of $1 \mathrm{mg} / \mathrm{l}$ which indicates inflammation ${ }^{(22)}$.

Total blood $\mathrm{Hg}$ concentrations increased gradually for each fish consumption group, with fish consumers having significantly greater concentrations than fish non-consumers (Table 3). Regular fish consumers ( $\geq 9$ times/30 d) had a seven-fold greater total blood $\mathrm{Hg}$ concentration than fish non-consumers $(4 \cdot 2(\operatorname{se~} 0 \cdot 7) v \cdot 0 \cdot 6(\operatorname{se~} 0 \cdot 05) \mu \mathrm{g} / \mathrm{l})$.

The associations between total blood log-transformed $\mathrm{Hg}$ concentrations and demographic variables were analysed using multiple linear regression analyses (Table 4). Women in the $30-39$ years and $40-49$ years age categories had significantly greater total blood $\mathrm{Hg}$ concentrations 
Fish, n-3 fatty acids and risk markers of CHD

Table 4 Regression model for $y=\log (\text { total blood } \mathrm{Hg})^{*}$ : sub-sample of women aged 16-49 years participating in the National Health and Nutrition Examination Survey 1999-2002

\begin{tabular}{|c|c|c|c|c|c|}
\hline \multirow[b]{2}{*}{ Characteristic } & \multirow[b]{2}{*}{$b$} & \multirow[b]{2}{*}{$95 \% \mathrm{Cl}$} & \multicolumn{2}{|c|}{ Total blood Hg $(\mu \mathrm{g} / \mathrm{l})$} & \multirow[b]{2}{*}{$P$} \\
\hline & & & Mean & SE & \\
\hline \multicolumn{6}{|l|}{ Age group } \\
\hline $16-19$ years & - & & 0.9 & $0 \cdot 1$ & \\
\hline $20-29$ years & 0.22 & $-0.05,0.48$ & $1 \cdot 3$ & $0 \cdot 1$ & $0 \cdot 103$ \\
\hline 30-39 years & 0.48 & $0.22,0.73$ & $1 \cdot 8$ & 0.2 & 0.001 \\
\hline 40-49 years & 0.65 & $0.34,0.96$ & $1 \cdot 8$ & 0.2 & $<0.0001$ \\
\hline \multicolumn{6}{|l|}{ Race/ethnicity } \\
\hline Non-Hispanic white & - & & $1 \cdot 5$ & $0 \cdot 1$ & \\
\hline Non-Hispanic black & 0.36 & $0 \cdot 14,0.58$ & $1 \cdot 7$ & 0.2 & 0.002 \\
\hline Mexican-American & $0 \cdot 10$ & $-0.06,0.26$ & $1 \cdot 2$ & $0 \cdot 1$ & $0 \cdot 201$ \\
\hline Other Hispanic and other & 0.31 & $-0.03,0.65$ & $2 \cdot 0$ & 0.4 & 0.075 \\
\hline \multicolumn{6}{|c|}{ Fish consumption frequency in past $30 \mathrm{~d}$} \\
\hline 0 & - & & $0 \cdot 6$ & 0.05 & \\
\hline $1-4$ times & $0 \cdot 83$ & $0.63,1.03$ & $1 \cdot 6$ & $0 \cdot 1$ & $<0.0001$ \\
\hline $5-8$ times & $1 \cdot 17$ & $0 \cdot 89,1 \cdot 45$ & $2 \cdot 2$ & 0.3 & $<0.0001$ \\
\hline$\geq 9$ times & $1 \cdot 76$ & $1 \cdot 41,2 \cdot 10$ & $4 \cdot 2$ & 0.7 & $<0.0001$ \\
\hline
\end{tabular}

${ }^{*}$ Adjusted for age, energy, BMI, education, ethnicity, physical activity, prescription drug use (anti-inflammatory or lipid-lowering), serum cotinine, vitamin C, Se, fibre, alcohol, MUFA and SFA.

than women aged 16-19 years. Compared with the other race/ethnicity groups, non-Hispanic blacks had significantly greater total blood $\mathrm{Hg}$ concentrations $(b=0 \cdot 36$, $95 \%$ CI $0 \cdot 14,0 \cdot 58)$. After adjusting for age, energy, BMI, education, ethnicity, physical activity, prescription drug use (anti-inflammatory or lipid-lowering), serum cotinine, vitamin C, Se, fibre, alcohol, MUFA and SFA, total blood $\mathrm{Hg}$ concentrations were significantly higher in all fish consumption groups compared with the fish non-eaters, indicating a high correlation between fish intake and total blood $\mathrm{Hg}$ concentrations.

\section{Fish consumption, C-reactive protein and lipid profile}

Initial analyses adjusting for age and energy demonstrated significant negative associations between total $30 \mathrm{~d}$ frequency of fish consumption and CRP concentrations $(b=-0 \cdot 10,95 \% \mathrm{CI}-0 \cdot 19,-0 \cdot 02)$ and significant positive associations with HDL-C concentrations $(b=1 \cdot 40$, 95\% CI $0 \cdot 31,2 \cdot 50)$. After adjustments for known risk factors for CHD (BMI, educational attainment, ethnicity, self-reported physical activity, self-reported use of antiinflammatory or lipid-lowering prescription drugs, serum cotinine, vitamin C, Se, fibre, alcohol, MUFA and SFA), there were no changes in the associations between $30 \mathrm{~d}$ frequency of fish consumption and CRP, but some attenuation with HDL-C concentrations (Table 5). There were no associations between $30 \mathrm{~d}$ frequency of fish consumption and TC and LDL-C in all models $(P>0 \cdot 05)$.

Sensitivity analyses conducted on the subset of women aged 16-49 years with measured data for TAG ( $n$ 577) demonstrated that after adjustment for age and other known CHD risk factors, $30 \mathrm{~d}$ frequency of fish consumption was negatively associated with TAG concentrations $(b=-4 \cdot 20,95 \% \mathrm{CI}-8 \cdot 00,-0 \cdot 33$; Table 5$)$.

\section{Fish consumption, C-reactive protein, blood lipids and total blood $\mathrm{Hg}$}

The addition of total blood $\mathrm{Hg}$ in Model 3 for CRP did not change the significant inverse association between fish consumption and CRP concentrations $(b=-0 \cdot 10,95 \%$ CI $-0 \cdot 18,-0 \cdot 03$; Table 5$)$. To test this effect and control for total blood $\mathrm{Hg}$, we calculated the average CRP concentration by fish non-consumer or fish consumer group and tertile of total blood $\mathrm{Hg}$ concentration (Table 6). Despite the findings that CRP concentrations among infrequent fish consumers were higher than for other groups (Table 3), this analysis, which controlled for total blood $\mathrm{Hg}$, showed that as $\mathrm{Hg}$ concentrations increased there was no significant change in CRP concentrations or in the association between CRP and fish consumption. This was most likely due to the categorization of all fish consumers into one group. The unweighted sample sizes were not adequate to conduct the analysis broken down by fish consumption levels.

The addition of total blood $\mathrm{Hg}$ in the Model 3 regression analyses showed attenuation of the association between total $30 \mathrm{~d}$ frequency of fish consumption and HDL-C concentrations to non-significant levels ( $b=0 \cdot 48,95 \% \mathrm{CI}-0 \cdot 60,1 \cdot 60, P=0 \cdot 372$; Table 5 ). To test this attenuation effect we calculated the mean HDL-C for fish non-consumers and fish consumers separated by tertile of total blood $\mathrm{Hg}$ concentration. Analyses of the association between fish consumption and HDL-C levels, controlling for $\mathrm{Hg}$ levels, showed that that the difference in HDL-C concentrations between fish nonconsumers and consumers across $\mathrm{Hg}$ tertiles did not decrease, implying that total blood $\mathrm{Hg}$ did not diminish the positive association between fish intake and HDL-C (Table 7).

Addition of total blood $\mathrm{Hg}$ in Model 3 for the relationship between total frequency of fish consumption and TAG 
Table 5 Summaries of regression models of CHD risk factors on $30 \mathrm{~d}$ fish frequency consumption ( $\mathrm{g} /$ person per d): sub-sample of women aged 16-49 years participating in the National Health and Nutrition Examination Survey 1999-2002

\begin{tabular}{|c|c|c|c|c|c|}
\hline \multirow[b]{2}{*}{ Dependent variable } & \multirow[b]{2}{*}{ Sample size } & \multirow[b]{2}{*}{ Model $R^{2}$} & \multicolumn{2}{|c|}{ Square-root of fish frequency } & \multirow[b]{2}{*}{$P$} \\
\hline & & & $b$ & $95 \% \mathrm{Cl}$ & \\
\hline \multicolumn{6}{|l|}{ CRP } \\
\hline Model $1^{*}$ & 1245 & 0.04 & $-0 \cdot 10$ & $-0.19,-0.02$ & 0.015 \\
\hline Model $2 \dagger$ & 1245 & 0.33 & -0.09 & $-0.15,-0.02$ & 0.011 \\
\hline Model 3¥ & 1245 & 0.33 & $-0 \cdot 10$ & $-0.18,-0.03$ & 0.010 \\
\hline \multicolumn{6}{|l|}{ HDL-C } \\
\hline Model $1^{*}$ & 1245 & 0.04 & $1 \cdot 40$ & $0.31,2 \cdot 50$ & 0.014 \\
\hline Model 2† & 1245 & 0.25 & $1 \cdot 00$ & $0.07,2 \cdot 00$ & 0.036 \\
\hline Model 3‡ & 1245 & 0.25 & 0.48 & $-0.60,1 \cdot 60$ & NS \\
\hline \multicolumn{6}{|l|}{ TC } \\
\hline Model $1^{*}$ & 1245 & $0 \cdot 12$ & $-1 \cdot 40$ & $-3 \cdot 20,0 \cdot 36$ & NS \\
\hline Model 2† & 1245 & $0 \cdot 15$ & $-0 \cdot 80$ & $-2 \cdot 70,1 \cdot 10$ & NS \\
\hline Model 3‡ & 1245 & $0 \cdot 15$ & $-1 \cdot 70$ & $-4 \cdot 50,1 \cdot 10$ & NS \\
\hline \multicolumn{6}{|l|}{ LDL-C } \\
\hline Model $1^{*}$ & 577 & 0.07 & $-2 \cdot 10$ & $-5 \cdot 10,0 \cdot 84$ & NS \\
\hline Model 2† & 577 & $0 \cdot 13$ & $-1 \cdot 80$ & $-4 \cdot 80,1 \cdot 20$ & NS \\
\hline Model 3‡ & 577 & $0 \cdot 13$ & $-2 \cdot 10$ & $-5 \cdot 30,1 \cdot 10$ & NS \\
\hline \multicolumn{6}{|l|}{ TAG } \\
\hline Model $1^{*}$ & 577 & 0.02 & $-4 \cdot 40$ & $-8.70,-0.02$ & 0.049 \\
\hline Model $2+$ & 577 & $0 \cdot 14$ & $-4 \cdot 20$ & $-8.00,-0.33$ & 0.034 \\
\hline Model 3‡ & 577 & $0 \cdot 14$ & $-2 \cdot 30$ & $-5 \cdot 90,1 \cdot 20$ & NS \\
\hline
\end{tabular}

CRP, C-reactive protein; HDL-C, HDL cholesterol; TC, total cholesterol; LDL-C, LDL cholesterol; NS, P>0.05.

${ }^{*}$ Adjusted for age and energy.

tAdjusted for Model 1 variables plus BMI, education, ethnicity, physical activity, prescription drug use (anti-inflammatory or lipidlowering), serum cotinine, vitamin C, Se, fibre, alcohol, MUFA and SFA.

$\ddagger$ Adjusted for Model 2 variables plus log(total blood $\mathrm{Hg}$ ) and the interaction term of log(total blood Hg) $\times$ square-root of fish frequency.

Table 6 Average C-reactive protein concentration by total blood mercury tertile and fish consumers $v$. fish nonconsumers $(\mathrm{mg} / \mathrm{dl})$ : sub-sample of women aged 16-49 years participating in the National Health and Nutrition Examination Survey (NHANES) 1999-2002

\begin{tabular}{|c|c|c|c|c|c|}
\hline \multirow[b]{2}{*}{ Fish group } & & \multicolumn{4}{|c|}{ Total blood Hg tertile } \\
\hline & & 1 & 2 & 3 & Total \\
\hline \multirow[t]{2}{*}{ Fish non-consumers } & Mean & $0 \cdot 14$ & $0 \cdot 17$ & $0 \cdot 14$ & $0 \cdot 15$ \\
\hline & $95 \% \mathrm{Cl}$ & $0.11,0.17$ & $0 \cdot 14,0 \cdot 20$ & $0.07,0.25$ & \\
\hline \multirow[t]{2}{*}{ Fish consumers } & Mean & $0 \cdot 17$ & $0 \cdot 13$ & $0 \cdot 15$ & 0.15 \\
\hline & $95 \% \mathrm{Cl}$ & $0 \cdot 14,0.20$ & $0 \cdot 11,0 \cdot 15$ & $0 \cdot 12,0 \cdot 18$ & \\
\hline Total & Mean & $0 \cdot 15$ & $0 \cdot 14$ & $0 \cdot 15$ & \\
\hline
\end{tabular}

Table 7 Average HDL cholesterol concentration by total blood mercury tertile and fish consumers $v$. fish non-consumers (mg/l): sub-sample of women aged 16-49 years participating in the National Health and Nutrition Examination Survey (NHANES) 1999-2002

\begin{tabular}{|c|c|c|c|c|c|}
\hline \multirow[b]{2}{*}{ Fish group } & & \multicolumn{4}{|c|}{ Total blood Hg tertile } \\
\hline & & 1 & 2 & 3 & Total \\
\hline Fish non-consumers & $\begin{array}{l}\text { Mean } \\
95 \% \mathrm{Cl}\end{array}$ & $\begin{array}{l}51 \cdot 5 \\
48 \cdot 8,54 \cdot 1\end{array}$ & $\begin{array}{l}54 \cdot 1 \\
48 \cdot 9,59 \cdot 3\end{array}$ & $\begin{array}{l}50 \cdot 4 \\
48 \cdot 0,52 \cdot 7\end{array}$ & $52 \cdot 2$ \\
\hline Fish consumers & $\begin{array}{l}\text { Mean } \\
95 \% \mathrm{Cl}\end{array}$ & $\begin{array}{l}52 \cdot 5 \\
50 \cdot 0,55 \cdot 1\end{array}$ & $\begin{array}{l}56 \cdot 6 \\
54 \cdot 6,58 \cdot 6\end{array}$ & $\begin{array}{l}59 \cdot 6 \\
57 \cdot 2,62 \cdot 0\end{array}$ & $57 \cdot 0$ \\
\hline Total & Mean & $52 \cdot 0$ & $56 \cdot 0$ & $58 \cdot 9$ & \\
\hline
\end{tabular}

resulted in a non-significant association between total frequency of fish and TAG concentrations $(b=-2 \cdot 30,95 \%$ CI $-5 \cdot 90,1 \cdot 20, P=0 \cdot 183$; Table 5). A follow-up analysis to test this effect controlling for total blood $\mathrm{Hg}$ (i.e. calculated average TAG by tertile of total blood $\mathrm{Hg}$ and fish consumption category) showed a decrease in TAG for each tertile of total blood $\mathrm{Hg}$, again demonstrating the high collinearity between fish consumption and total blood $\mathrm{Hg}$ concentrations $(103 \cdot 8,102 \cdot 4$ and $94.6 \mathrm{mg} / \mathrm{dl}$ per tertile of total blood $\mathrm{Hg}$ ). Despite the high collinearity, the TAG concentrations for fish consumers were consistently lower than those of fish non-consumers $(99 \cdot 7 v .102 \cdot 3 \mathrm{mg} / \mathrm{dl})$. 


\section{Discussion}

The results of the present study suggest an association between frequent fish intake and selected risk markers of CHD (HDL-C, TAG and CRP) in women aged 16-49 years. As the total $30 \mathrm{~d}$ frequency of fish consumption increased, concentrations of HDL-C increased while concentrations of TAG and CRP decreased. When total blood Hg was introduced into the regression models, the significant associations between frequent fish intake and CRP remained the same although the association with HDL-C was diminished. Further analyses controlling for total blood $\mathrm{Hg}$ demonstrated that this latter effect is most likely due to collinearity between fish intake and total blood $\mathrm{Hg}$. There was no longer an association between fish consumption and TAG once the total blood $\mathrm{Hg}$ and fish interaction was added to the model. This may be attributed to the small sample size since the TAG analyses were conducted on a subset of the population, or it may be possible that adding $\mathrm{Hg}$ to the model may have led to over-controlling for variables as $\mathrm{Hg}$ and fish consumption are highly correlated. No significant associations were seen between fish intake and either LDL-C or TC concentrations.

Consumption of DHA and EPA and fish containing these fatty acids has been shown to reduce blood concentrations of LDL-C, TC and TAG and to raise concentrations of HDL-C ${ }^{(5-7)}$. The average DHA + EPA intake in our study $(0 \cdot 1 \mathrm{~g} / \mathrm{d})$ was much lower in comparison to that of other studies. Our results agree with other studies which have shown that fish intake or markers of fish intake (plasma PUFA) do not significantly impact LDL-C or TC levels ${ }^{(17,23)}$. The $24 \mathrm{~h}$ calculated DHA + EPA intake in our study was also less than the American Heart Association (AHA) recommendation (at least $0 \cdot 5-1 \cdot 0 \mathrm{~g}$ of $n$-3 fatty acids daily to achieve cardioprotective effects), which may explain the lack of association in the models where HDL-C, LDL-C and TC were the independent variables $^{(24)}$. When $24 \mathrm{~h}$ dietary intake of DHA + EPA was used as a marker of fish consumption there were no associations with risk markers of CHD. The lack of association may be due to the fact that fish intake is variable and a single $24 \mathrm{~h}$ recall does not capture foods that are eaten on an irregular basis.

Organic (methyl) $\mathrm{Hg}$ is present in fish due to its uptake from environmental sources ${ }^{(11)}$. In man, the sole source of exposure to organic $\mathrm{Hg}$ is the consumption of fish and sea mammals ${ }^{(12)}$. Research has linked $\mathrm{Hg}$ ingestion from fish to increased risk of CHD in men ${ }^{(15-17,23,25)}$. In our study of women aged 16-49 years we found a protective association between fish intake and CHD risk factors. Analyses of the association between fish consumption and HDL-C levels, controlling for Hg levels, showed that the difference in HDL-C concentrations between fish nonconsumers and consumers across $\mathrm{Hg}$ tertiles did not decrease, implying that $\mathrm{Hg}$ did not diminish the positive association between fish intake and HDL-C. Inconsistent relationships between biomarkers of $\mathrm{Hg}$ and $\mathrm{CHD}$ risk have been reported, perhaps due to differences in the ages of the study subjects, frequency of fish consumption among populations studied, type of fish consumed and health status of the study samples ${ }^{(18,23,26)}$.

CRP is a predictor of CHD risk $^{(27)}$ and is affected by numerous lifestyle variables. In general, individuals with elevated CRP concentrations tend to smoke, have high blood pressure, are overweight and fail to exercise ${ }^{(28)}$. A few studies have evaluated the effects of dietary intakes of DHA + EPA on CRP concentrations and other biomarkers of inflammation in different samples of subjects and have produced varying results ${ }^{(29,30)}$.

The present cross-sectional study extends the results of previous studies using the NHANES data set (1999-2000). The average total blood $\mathrm{Hg}$ was higher for the 1245 women (aged 16-49 years) in the current study than $\mathrm{Hg}$ levels reported from the same data set using a different sample of 1709 women $(1.6 v .1 .02 \mu \mathrm{g} \mathrm{Hg} / 1)^{(31)}$. Schober et al. also reported that women who ate 3 or more servings of fish (in the past $30 \mathrm{~d}$ ) had four-fold greater geometric mean $\mathrm{Hg}$ concentrations compared with women not consuming fish ${ }^{(31)}$. A second study that analysed hair $\mathrm{Hg}$ data reported three-fold higher hair $\mathrm{Hg}$ concentrations in frequent fish consumers ( $\geq 3$ times in the past $30 \mathrm{~d}$ ) than in non-consumers ${ }^{(32)}$. In the current study, there was a seven-fold difference in total blood $\mathrm{Hg}$ concentration between women who consumed fish $\geq 9$ times/30 d and the fish non-consumers. The differences between studies are most likely due to how the fish consumption groups are stratified and the sample sizes within these groups.

When total blood $\mathrm{Hg}$ data were analysed by race/ ethnicity, the results of the current study are consistent with two recent reports that analysed relationships between calculated organic blood $\mathrm{Hg}$ (rather than total blood $\mathrm{Hg}$ concentrations), hair $\mathrm{Hg}$ concentrations and fish intake during the first two years of the NHANES $(1999-2000)^{(32,33)}$. The lowest blood organic Hg concentrations were in Mexican-Americans and the highest concentrations were in participants who designated themselves in the 'other' racial/ethnic category, which included Asians, Native Americans and Pacific Islanders $^{(33)}$. Mahaffey et al. reported that women aged 30-49 years have blood organic $\mathrm{Hg}$ concentrations 1.5 times greater than women aged $16-29$ years ${ }^{(33)}$. Similarly, we found a two-fold difference in total blood $\mathrm{Hg}$ concentrations between women aged $16-19$ and 30-39 years $(1 \cdot 0(\operatorname{se~} 0 \cdot 1) v \cdot 2 \cdot 0(\operatorname{se~} 0 \cdot 3) \mu \mathrm{g} / 1)$.

Only fifty-seven women in our sample reported consuming fish $\geq 9$ times in the past $30 \mathrm{~d}$, a frequency similar to the AHA recommendation of eating fish at least twice weekly. Most of the women were either fish non-consumers ( $n$ 441) or light fish consumers (1-4 times/30 d, $n$ 166), and thus failed to meet the AHA guideline for fish. 
Our study was limited to a sub-sample of women aged 16-49 years in the NHANES (1999-2002) data set for whom total blood $\mathrm{Hg}$ data were available. Therefore, these results cannot be generalized to other population groups. Inherent to a large cross-sectional study is the temporality of the data; therefore, in the present observational and cross-sectional study we cannot exclude the possibility that the association between fish and CHD risk factors may be due to unmeasured variables. However, we controlled for all variables currently known to affect risk of CHD. Alternatively, the study would have been strengthened if actual disease endpoints could have been used; however, the age group of the study sample was prohibitive of such analysis.

$n-6$ and n-3 PUFA compete during metabolism and an excessive intake of $n-6$ fatty acids may attenuate the cardioprotective benefits normally seen with $n$-3 PUFA. In a large prospective cohort study, Mozaffarian et al. investigated the joint effects of different PUFA on the risk of CHD in men. These researchers saw benefits in the combination of plant- and marine-based $n$ - 3 PUFA on CHD risk independent of $n-6$ PUFA consumption. They concluded that non-marine-based $n$-3 PUFA are beneficial in reducing risk of $\mathrm{CHD}$, especially when populations do not have easy access or availability to marine sources ${ }^{(34)}$. The interplay of plant-derived and marine-derived $n$ - 3 fatty acids was not analysed in the current study.

The results of the present study would have been strengthened if data on LDL-C and TAG had been available for more subjects, since both of these lipid biomarkers may be affected by $n-3$ PUFA $^{(12)}$. However, the analysis on a subpopulation did not show any association between $n$-3 fatty acids and these blood lipids. Other inflammatory biomarkers such as IL-6 or other cytokines may be better indicators of CHD risk than CRP, but these data were not available in the current NHANES surveys.

A strength of the current study is that a $30 \mathrm{~d}$ frequency of fish intake was used which provides a good estimate of habitual intake. Also, the current study included healthy women of childbearing age, whereas studies that examined the joint association between fish intake, $\mathrm{MeHg}$ and $\mathrm{CHD}$ only included men and older women. Finally, because the NHANES data set is large, we were able to control for a number of demographic and lifestyle variables.

\section{Summary}

The results of the present study provide further support for recommending regular fish consumption along with maintaining a healthy lifestyle (e.g. not smoking and getting daily moderate exercise) as a way of reducing the risk of CHD. The effect of $\mathrm{Hg}$ on biomarkers of inflammation is unclear. Based on this study and others, it appears that the levels of $\mathrm{Hg}$ in fish consumed by this population may not be high enough to counteract the positive association between fish intake and CHD risk factors.

\section{Acknowledgements}

K.M.S., the lead author, was responsible for the article's conception and design, acquisition of data, analysis and interpretation of data, drafting and critical revision of the manuscript, and the statistical analyses. N.R.S., the lead advisor, was also responsible for the conception and design, interpretation of data, drafting and critical revisions of the manuscript. L.M.B. did extensive reviews of the manuscript, statistical methodology and data interpretation. M.K. helped in critical review of the study design and revising the manuscript. There are no conflicts of interest. No funding was received for this project.

\section{References}

1. Weber P \& Raederstorff D (2000) Triglyceride-lowering effect of omega-3 LC-polyunsaturated fatty acids - a review. Nutr Metab Cardiovasc Dis 10, 28-37.

2. Calder P (2004) n-3 Fatty acids and cardiovascular disease: evidence explained and mechanisms explored. Clin Sci (Lond) 107, 1-11.

3. Oomen CM, Feskens EJ, Räsänen L, Fidanza F, Nissinen AM, Menotti A, Kok FJ \& Kromhout D (2000) Fish consumption and coronary heart disease mortality in Finland, Italy and the Netherlands. Am J Epidemiol 151, 999-1006.

4. Roche H \& Gibney M (2000) Effects of long-chain $n$-3 polyunsaturated fatty acids on fasting and postprandial triacylglycerol metabolism. Am J Clin Nutr 71, Suppl., 232S-237S.

5. Lopez-Garcia E, Schulze MB, Manson JE, Meigs JB, Albert CM, Rifai N, Willett WC \& Hu FB (2004) Consumption of $(n-3)$ fatty acids is related to plasma biomarkers of inflammation and endothelial activation in women. $J$ Nutr 134, 1806-1811.

6. Kelley DS, Siegel D, Vemuri M \& Mackey BE (2007) Docosahexaenoic acid supplementation improves fasting and postprandial lipid profiles in hypertriglyceridemic men. Am J Clin Nutr 86, 324-333.

7. Agren JJ, Hanninen O \& Julkunen A (1996) Fish diet, fish oil and docosahexaenoic acid rich oil lower fasting and postprandial plasma lipid levels. Eur J Clin Nutr 50, $765-771$.

8. Konig A, Bouzan C, Cohen J, Connor W, Kris-Etherton P, Gray G, Lawrence RS, Savitz DA \& Teutsch SM (2005) A quantitative analysis of fish consumption and coronary heart disease mortality. Am J Prev Med 29, 335-346.

9. Jong M, Hofker M \& Havekes L (1999) Role of ApoCs in lipoprotein metabolism: functional differences between ApoCI, ApoC2, and ApoC3. Aterioscler Thromb Vasc Biol 19, 472-484.

10. Harris W \& Bulchandani D (2006) Why do omega-3 fatty acids lower serum triglycerides? Curr Opin Lipidol 17, 387-393.

11. Agency for Toxic Substances and Disease Registry (1999) TOXFAQs $^{\text {TM }}$ for mercury. http://www.atsdr.cdc.gov/ tfacts46.html (accessed September 2008).

12. Clarkson TW, Magos L \& Myers GJ (2003) The toxicology of mercury - current exposures and clinical manifestations. $N$ Engl J Med 349, 1731-1737.

13. National Research Council (2000) Toxicological Effects of Methyl Mercury. Washington, DC: National Academy Press.

14. US Department of Health and Human Services and US Environmental Protection Agency (2004) FDA and EPA 
Announce the Revised Consumer Advisory on Methylmercury in Fish. http://www.fda.gov/bbs/topics/news/ 2004/NEW01038.html (accessed September 2008).

15. Guallar E, Sanz-Gallardo MI, van't Veer P, Bode P, Aro A, Gómez-Aracena J, Kark JD, Riemersma RA, Martín-Moreno JM \& Kok FJ; Heavy Metals and Myocardial Infarction Study Group (2002) Mercury, fish oils, and the risk of myocardial infarction. N Engl J Med 347, 1747-1754.

16. Salonen JT, Nyyssönen K \& Salonen R (1995) Fish intake and the risk of coronary disease. N Engl J Med 333, 937.

17. Rissanen T, Voutilainen S, Nyyssönen K, Lakka TA \& Salonen JT (2000) Fish oil-derived fatty acids, docosahexaenoic acid and docosapentaenoic acid, and the risk of acute coronary events: the Kuopio ischaemic heart disease risk factor study. Circulation 102, 2677-2679.

18. Yoshizawa K, Rimm EB, Morris JS, Spate VL, Hsieh CC, Spiegelman D, Stampfer MJ \& Willett WC (2002) Mercury and the risk of coronary heart disease in men. $N$ Engl J Med 347, 1755-1760.

19. von Schacky C, Angerer P, Kothny W, Theisen K \& Mudra H (1990) The effect of dietary omega-3 fatty acids on coronary atherosclerosis. A randomized double-blind, placebo-controlled trial. Ann Intern Med 130, 554-562.

20. National Center for Health Statistics (2008) National Health and Nutrition Examination Survey. Data Sets and Related Documentation. http://www.cdc.gov/nchs/about/major/ nhanes/datalink.htm (accessed September 2008).

21. Bland J \& Altman D (1996) Transforming data. BMJ 312, 770 .

22. American Heart Association (2006) Learn and Live. Inflammation, Heart Disease and Stroke: The Role of C-Reactive Protein. http://www.americanheart.org/presenter. jhtml?identifier $=4648$ (accessed September 2008).

23. Hallgren C, Hallmans G, Jansson J, Marklund S, Huhtasaari F, Schutz A, Strömberg U, Vessby B \& Skerfving S (2001) Markers of high fish intake are associated with decreased risk of a first myocardial infarction. Br J Nutr 86, 397-404.

24. Kris-Etherton P, Harris W \& Appel L (2002) AHA Scientific Statement. Fish consumption, fish oil, omega-3 fatty acids and cardiovascular disease. Circulation 106, 2747-2757.

25. Virtanen JK, Voutilainen S, Rissanen TH, Mursu J, Tuomainen TP, Korhonen MJ, Valkonen VP, Seppanen K,
Laukkanen JA \& Salonen JT (2005) Mercury, fish oils, and risk of acute coronary events and cardiovascular disease, coronary heart disease, and all-cause mortality in men in eastern Finland. Aterioscler Thromb Vasc Biol 25, 228-233.

26. Ahlqwist $M$, Bengtsson C, Lapidus L, Gergdahl IA \& Schütz A (1999) Serum mercury concentration in relation to survival, symptoms, and diseases: results from the prospective population study of women in Gothenburg, Sweden. Acta Odontol Scand 57, 168-174.

27. Ridker PM, Hennekens CH, Buring JE \& Rifai N (2000) C-reactive protein and other markers of inflammation in the prediction of cardiovascular disease in women. $\mathrm{NEnglJ}$ Med 342, 836-843.

28. Ridker PM (2003) C-reactive protein. A simple test to help predict risk of heart attack and stroke. Circulation 108, e81-e85.

29. Vega-Lopez S, Kaul N, Devaraj S, Cai RY, German B \& Jialal I (2004) Supplementation with omega3 polyunsaturated fatty acids and all-rac $\alpha$-tocopherol alone and in combination failed to exert an anti-inflammatory effect in human volunteers. Metabolism 53, 236-240.

30. Stark KD \& Holub BJ (2004) Differential eicosapentaenoic acid elevations and altered cardiovascular disease risk factor responses after supplementation with docosahexaenoic acid in postmenopausal women receiving and not receiving hormone replacement therapy. Am J Clin Nutr 79, 765-773.

31. Schober SE, Sinks TH, Jones RL et al. (2003) Blood mercury levels in US children and women of childbearing age, 1999-2000. JAMA 289, 1667-1674.

32. McDowell MA, Dillon CF, Osterloh J et al. (2004) Hair mercury levels in US children and women of childbearing age: reference range data from NHANES 1999-2000. Environ Health Perspect 112, 1165-1171.

33. Mahaffey KR, Clickner RP \& Bodurow CC (2003) Blood organic mercury and dietary mercury intake: National Health and Nutrition Examination Survey, 1999 and 2000. Environ Health Perspect 112, 562-570.

34. Mozaffarian D, Ascherio A, Hu FB, Stampfer MJ, Willett WC, Siscovick DS \& Rimm EB (2005) Interplay between different polyunsaturated fatty acids and risk of coronary heart disease in men. Circulation 111, 157-164. 